\title{
REFLEXIONES SOBRE LA RELIGIÓN COMO SABER DE SALVACIÓN \\ DESDE El PENSAMIENTO de MaRÍA ZAMBRANO
}

\section{Reflections around the religion how to know of salvation from the thought of María Zambrano}

\author{
CARMEN VILLORA SÁNCHEZ \\ Centro de Enseñanza Superior en Humanidades y Ciencias de la Educación Don Bosco. \\ Adscrito a la Universidad Complutense/ Madrid-España \\ cvillora@cesdonbosco.com \\ Código Orcid: https//orcid.org/0000-000 1-9709-8873
}

\begin{abstract}
Resumen
Este artículo surge a raíz de una tesis doctoral sobre el pensamiento religioso de María Zambrano. Aunque brota de dicha investigación, no pretende exponer de manera exhaustiva las líneas de trabajo y las conclusiones desarrolladas en ella. Se trata de presentar los núcleos temáticos centrales del pensamiento religioso de Zambrano, enriqueciendo con textos de la autora, las convicciones expuestas. La metodología seguida consiste en la exposición de los conceptos claves del pensamiento religioso de María Zambrano. Se parte de la crítica al racionalismo, para proponer, la razón poética. Una razón que tiene que ver con la vida, un saber de experiencia que inicia la apertura de la persona y la conduce hacia lo sagrado. A continuación se expone el aspecto central del pensamiento religioso zambraniano, el sentir originario. Un sentir y pensar en el que la persona recibe la revelación de sí misma, descubriendo dos aspectos centrales del ser humano: la vocación a la unificación, interioridad; y la llamada a la relación con el Otro y con los otros, alteridad. Por último se torna a la vida para transformarla y manifestar que la persona nueva es capaz de piedad, fraternidad, misericordia y perdón. En las conclusiones se valora la aportación de la autora con la crítica al racionalismo y su propuesta de la religión como saber de salvación para todo ser humano.
\end{abstract}

Palabras claves

Saber de experiencia, razón poética, sentir originario, piedad, misericordia, fraternidad.

Forma sugerida de citar: Víllora Sánchez, Carmen (2018). Reflexiones sobre la religión como saber de salvación desde el pensamiento de María Zambrano. Sophia: Colección de Filosofía de la Educación, 24(1), pp. 87-107.

* Doctora en Filosofía (PhD). Profesora titular, Área de Ciencias Sociales en el Centro de Enseñanza Superior en Humanidades y Ciencias de la Educación Don Bosco adscrito a la Universidad Complutense de Madrid. 
Abstract

This article issues from a doctoral thesis on Maria Zambrano's religious thought. Although it arises from that research, it doesn't try to show thoroughtly the lines of work or the conclusions developed in it.

It is about presenting the central thematic nucleus of religious thought of Zambrano. Enriching with texts of her writings the convictions exposed. The methodology followed consists of the presentation of the key concepts of the religious thought of María Zambrano. It starts from the criticism to rationalism, to advance exposing the philosophical proposal of Zambrano, the poetic reason. A thinking that has to deal with life, a knowledge of experience that initiates the opening of the person and leads to the sacred. Below is the central aspect of Zambian religious thought, the original feeling. From the origin of feeling and thinking the person receives the revelation of himself. Discovering two central aspects of the human being: the vocation to unification, interiority and the call to the relationship with the Other and with others, otherness. Lastly, it turns to life to transform it and to manifest the new person capable of piety, fraternity and mercy. In the conclusions the author's contribution to the criticism of rationalism is valued and the methodological proposal of the philosopher is advanced, for every human being, religion how to know salvation.

Knowledge of experience, poetic reason, native feel, Piety, Mercy, Forgiveness, Fraternity.

\section{Introducción}

En Delirio y destino María Zambrano escribe: "Mi vida no es mi sueño [...] Dios nos sueña y entonces hay que hacer que su sueño sea lo más transparente posible" (1998, p. 24). De esta manera la autora nos quiere mostrar cuál es la tarea que nos compete, alejar las sombras y expresar con una vida, transparente y lúcida, el sueño de Dios. Porque para la filósofa la persona no es solo un ser histórico y estático sino que es un ser destinado a la progresiva creación de sí misma.

La metáfora del nacimiento, tan sugerente en la filosofía zambraniana, expresa la idea de "estar continuamente en trance de nacimiento" (Zambrano, 1988, p. 113). Esto conlleva, para la autora, una promesa que no es posible abolir. "La promesa de ser concebido y de irse al par concibiendo enteramente, aunque no se vea el término, ni la meta” (Zambrano, 1990, p. 24). De este modo la existencia humana se comprende como un estar naciendo constantemente, oscila entre lo que la persona va siendo y lo que quiere ser. "Y es que parece ser condición de la vida humana tener que renacer, el haber de morir y resucitar sin salir de este mundo" (Zambrano, 2005, p. 18)

Así pues, desde su raíz orteguiana, la vida para ella aparece como una tarea irrenunciable que consiste en ir haciéndose. Un quehacer que supone responsabilidad y exige la propia implicación. Desde esta clave, la persona ha de ir desentrañándose o construyéndose continuamente a sí misma. En esto consiste la existencia plena. María Zambrano en sus 
escritos asigna esta comprometida tarea al ser humano, lo sitúa con una fuerte responsabilidad frente a su propia vida.

La fuerza de su aportación reside en esta peculiar forma de evocar y convocar la existencia, como sabiduría que sabe dar cuenta de la vida y, al mismo tiempo, la supera. Así lo describe la propia autora:

Hay verdades, las de la ciencia, que no ponen en marcha la vida. Las verdades de la vida son las que, introduciéndose en ella, la hacen moverse, ordenadamente; las que la encienden y sacan de sí, haciéndola trascender y poniéndola en tensión (Zambrano, 2005, p. 90).

Zambrano primeramente lo vivió, recorrió un camino personal, lo quiso convertir en método y proponerlo como tal; intentó describirlo mientras lo recorría. En El hombre y lo divino lo expresa de este modo:

Transformar el simple vivir, la vida que se nos ha entregado y que llevamos de un modo inerte, en eso que se ha llamado experiencia. Experiencia que forma esa primera capa, la más humilde, del saber "de las cosas de la vida" y sin la cual ningún antiguo hubiera osado llamarse filósofo (Zambrano, 2011a, p. 225).

El aspecto central de su filosofía es una invitación a transformar la vida, es un saber de salvación, un saber religioso. Zambrano nos provoca a entrar en nosotros mismos, donde encontramos nuestra propia indigencia y de este modo se nos revela la necesidad de salir de nosotros mismos en busca de salvación. Para la filósofa de Málaga esta tarea la desarrolla la persona a lo largo de su vida, por eso sus escritos se ofrecen como luz a quienes la leen, porque para ella la escritura es dar a conocer lo que se ha descubierto y ofrecerlo a otros.

En la literatura de María Zambrano, la persona que busca la transcendencia será el eje central, también desarrolla con su escritura otras temáticas que auxilien al ser humano en esta importante tarea que le compete. Estos temas son la actividad política, ética, religiosa y educati$\mathrm{va}^{1}$. Este artículo parte de la razón poética y describe el aspecto religioso.

Las personas conocedoras de su filosofía consideran que desde el punto de vista religioso se podría entender todo su pensamiento, se considera como el eje central alrededor del cual gira toda su obra. Ella misma lo intuyó así, por eso en el prólogo a la segunda edición de El hombre y lo divino, comentaba: "No está en este pensamiento hacer de El hombre y lo divino el título general de los libros por mí dados a la imprenta, ni de los que están camino de ella. Más no creo que haya otro que mejor les conviniera" (Zambrano, 2011a, p. 99). 
El presente artículo parte de la concepción del ser humano como ser en construcción para demostrar que María Zambrano concibe la persona como ser esencialmente religioso. Este objetivo se realizará describiendo algunos núcleos temáticos centrales de su pensamiento, fundamentalmente a partir de sus escritos. Muchos son los textos, especialmente a partir del centenario de su nacimiento año 2004, que interpretan sus pensar y su filosofía, incluso el aspecto religioso; pero esta aportación pretende fundamentar las afirmaciones expuestas basándose directamente en sus escritos, aunque se tiene presente la literatura sobre la autora.

La metodología consiste en la exposición de los conceptos claves del pensamiento religioso de María Zambrano, enriqueciendo con textos de sus escritos, las convicciones expuestas.

En cuanto al contenido, se parte de la crítica al idealismo racional, para describir un saber de experiencia que inicia la apertura de la persona y la conduce hacia lo sagrado. Una razón que tiene que ver con la vida, razón poética. A continuación se expone el aspecto central del pensamiento religioso zambraniano, el sentir originario, desde él la persona recibe la revelación de sí misma. De este modo, descubrirá dos aspectos centrales del ser humano: la vocación a la unificación, la interioridad y la llamada a la relación con el Otro y con los otros, la alteridad. De este modo se torna a la vida para transformarla, manifestando que la persona nueva es capaz de piedad, fraternidad, misericordia y perdón. En las conclusiones se valora la aportación de la autora que propone la religión como saber de salvación para todo ser humano.

\section{Saber de experiencia}

Iniciada por su maestro, Ortega y Gasset, en el concepto de razón vital ${ }^{2}$, Zambrano avanzará y seguirá el curso de una razón sentida, en sintonía con escritos de Unamuno y Machado que ella conoce bien e incorpora a su pensar. De este modo Zambrano colaboró en la renovación profunda de la filosofía racionalista dominante de su época.

Anteriormente autores como Husserl, Heidegger, Ortega y Gasset, Adorno, Horkheimer, Benjamin, etc. había anunciado la crisis de la razón moderna; enlazando ella propone otro tipo de razón.

También el pensamiento zambraniano se encuentra en sintonía con un grupo de autoras contemporáneas como Rosa Luxemburgo, Edith Stein, Hannah Arendt, Simone de Beauvoir y Simone Weil; "ellas han contribuido a cambiar, con su palabra y su testimonio, la expresión intelectual del siglo pasado" (Víllora Sánchez, 2015b, p. 102). 
La filósofa malagueña critica el racionalismo cartesiano, que cosifica a Dios y nos aleja de su presencia, sitúa la conciencia en el lugar de Dios. La razón moderna ubica la conciencia sin referencias, cerrada en sí misma. Es una razón que no cuenta con los sentimientos, los sueños, la fe, la esperanza; en definitiva, razón que no tiene en cuenta la vida. El pensamiento de María Zambrano se aleja del racionalismo, discurso cerrado sobre sus propias razones, y busca una filosofía que pase por una razón que también cuente con la vida. Porque desde el racionalismo la vida se vuelve estéril y "pierde su capacidad de transcender, de ir siempre más allá; el punto al que nos ha conducido el 'caminar racionalista' encontraría su alternativa en la vida emocional. El mundo del sentir, comprendido entre el intelecto y la sensación" (Revilla, 2013, p. 158).

Desde esta crítica a la razón idealista ella "alumbró un nuevo modo de filosofar desde las mismas entrañas de la vida, poniendo al descubierto aquello que el racionalismo había ocultado o reprimido, las otras razones del corazón” (Cerezo Galán, 2004, párr. 5).

La filosofa veleña al analizar las consecuencias del idealismo que se alejó de la realidad va sugiriendo una metafísica más modesta, "propone un pensamiento a la medida del hombre. No se trata en la filosofía de dominar el mundo, sino de algo que es previo, de conocerlo, de dejarse más bien poseer y acariciar por su armonía y por su belleza" (Ortega Muñoz, 2010, p. 202). Abandonando la filosofía utilitarista que ve la realidad desde las necesidades o deseos propone un giro copernicano para captar la esencia del conocimiento humano que se desarrolla en tres fases: "una intuición sensible que nos aportan los sentidos, una intuición intelectual, que nos manifiesta una serie de principios y verdades que nos hacen posible pensar y una capacidad discursiva que en virtud de estos principios juzga y razona" (2010, p. 203).

Con el racionalismo, el ser humano ha perdido la capacidad de tratar con el misterio. La consecuencia de este desarraigo es la soledad y lo expresa así: $\mathrm{Y}$ así hemos venido a quedar solos; solos e inhábiles para tratar con 'lo otro'. Pero, si reunimos las diversas clases de 'lo otro', vemos que es nada menos que la realidad, la realidad que nos rodea y en la cual estamos enclavados (Zambrano, 1989a, p. 19).

¿Cómo salir de la crisis de la racionalidad? La salida a la crisis de la razón moderna está en la recuperación del sentimiento íntimo, desde las entrañas de Dios. Esto para Zambrano va más allá de un simple pensar en lo divino, es descubrir el Dios cristiano del amor, "ese Dios cordial que nos despierta la fraternidad universal, la copertenencia al mundo" (Zambrano, 2003, p. 25). 


\section{Razón poética: como una gota de aceite}

El pensamiento de María Zambrano se origina, allí donde el sol o la luz se alzan, "pues vivir humanamente debe de ser ir sacando a la luz el sentir, el principio oscuro y confuso, ir llevando el sentir a la inteligencia" (Zambrano, 1998, pp. 100-101).

El hecho de que su filosofía se apoye en un saber de experiencia, no le hace renunciar a la razón. Ella contará con una razón que no se inmoviliza en análisis y deducciones; sino que adquiere su equilibrio, siguiendo el ritmo del latir del corazón. Complementa la razón con el movimiento trascendente de la vida:

Será la actuación continua y humilde de una razón que no ha comenzado por nombrarse a sí misma, por establecerse a sí misma; de una razón o manera de conocimiento que se ha extendido humildemente por seres y cosas, sin delimitarse previamente a sí propia; que ha actuado sin definirse ni separarse, mezclándose; inclusive, con la razón al uso, con su enemiga y dominadora razón racionalista. Pero es que una de las características de tal género de razón sería el no tomar represalias contra lo que la domina, el no tomar represalias más que en el terreno de la creación, rebasando, superando -jamás rebatiendo ni disputando-. Razón esencialmente antipolémica, humilde, dispersa, misericordiosa (Zambrano, 1986, pp. 125-126).

Es la razón, mediadora que busca adentrarse en las "raíces de lo humano", que pretende abrir un claro en medio del bosque: "Abrir, abrir la Razón, uniendo razón y piedad, razón y sentir originario, filosofía y poesía" (Zambrano, 2002, p. 195).

En Séneca encuentra Zambrano una razón mediadora como la que ella busca. La describe así: "porque el pensamiento que de él dimana no es coactivo; y tiene algo de musical. Son acordes que acallan, aduermen y suavizan" (Zambrano, 1992, p. 16). Y esta es la filosofía a la que se acoge la autora por el bien que proporciona. "Es la filosofía, la razón compadecida de la condición desvalida del hombre. Es, en cierto modo, la entrada de la misericordia y de la piedad en la razón antigua" (1992, p. 19).

Una filosofía de la visión interior, una filosofía de la luz, de la aurora. Es la razón asistida por el corazón para que esté presente la persona en su integridad.

Su filosofía es llevar la vida al lenguaje, dar voz a lo que pide ser sacado del silencio, a los niveles de realidad que difícilmente encuentran el modo de acceder a la palabra. Es el modo propio de discurrir de María Zambrano, ajeno a las abstracciones, para evitar el riesgo de sofocar la vida humana, objeto principal de sus reflexiones. En un primer momento 
lo llamará razón mediadora, pero en el poso de su escritura llegará a la "Razón poética", entendida como relación del pensamiento y la experiencia, que hace posible unificar conciencia y vida.

María Zambrano, en carta a Rafael Dieste, describe así la razón poética:

Hace ya años, en la guerra sentí que no eran "nuevos principios ni una Reforma de la Razón", como Ortega había postulado en sus últimos cursos, lo que ha de salvarnos, sino algo que sea razón, pero más ancho, algo que se deslice también por los interiores, como una gota de aceite que apacigua y suaviza, una gota de felicidad. Razón poética... es lo que vengo buscando. Y ella no es como la otra, tiene, ha de tener muchas formas, será la misma en géneros diferentes (Zambrano, 1991, p. 102).

La metáfora de la gota de aceite será la imagen que, para la escritora, mejor recoja lo que quiere transmitir. Así en La agonía de Europa, afirma: "se tenía que sentir la gota de aceite llena de sabiduría que evita, dada a tiempo la cerrazón de las entrañas, su petrificación. Y el hombre, ser de interioridad, no puede permanecer mucho tiempo con ellas cerradas o vacías" (Zambrano, 2004, p. 115).

La razón poética implica ir a la parte oculta de la vida de la persona y traerla a la posibilidad de la razón lúcida a través de la palabra. Entrar en el centro de la persona es la tarea fundamental de la razón poética, como método de conocimiento para llegar a descifrar lo que se siente. En definitiva, la razón poética trata de un pensar que quiere hacer público e inteligible la interioridad del ser humano.

La metafísica basada en la experiencia de la razón poética zambraniana, es un modo de hacer filosofía semejante al de Agustín de Hipona en las Confesiones, que busca la conversión de la vida, antes que el conocimiento de la verdad erudita. Conversión de la existencia que significa para Zambrano encauzar la propia vida hacia una verdad capaz de transformarla. A esta plenitud aspira el ser humano "la verdad transforma la vida" (Zambrano, 1988, p. 13).

Para la estudiosa del pensamiento zambraniano, A. Bundgård, la transformación se realiza desde el amor, que nos muestra a Dios: "La razón poética es un logos que se inscribe en la tradición cristiana ya que no intenta conceptualizar el misterio de Dios, sino desvelar mediante un acto de amor algo de lo que Dios es. En este sentido, la razón poética es una razón teologal y espiritual” (Bundgård, 2000, p. 75).

La razón poética está cargada de misericordia, de amor, de trato y relación con los otros... sentimientos que guían a la plenitud de la vida 
humana y a la trascendencia. "La razón poética trata, en definitiva, de un pensar que quiere hacer pública e inteligible la interioridad del ser humano" (Víllora Sánchez, 2015a, p. 178).

\section{Sentir originario}

Con la propuesta de esta razón María Zambrano busca la claridad de las vivencias humanas para facilitar su comprensión. La razón poética invade la persona, como gota de aceite que lentamente se expande por las entrañas dulcificándolas y la lleva a descubrir el sentir originario. Es un saber que sentimos, que viene desde el origen y posibilita conocer lo más hondo de nuestra vida, nuestra interioridad. La filósofa lo describe así: "buscamos la experiencia originaria en lo más hondo, en lo más alto, en todas partes, a ver si la encontramos" (1987a, p. 70).

Este saber es metafísico porque busca una experiencia originaria. Intenta orientar sobre la vida humana, sabiendo que esta tiene un origen, que hay un centro que dimana fuerza y armonía. En definitiva, un conocimiento que no se basa en la simple comprensión, un saber de revelación. Y ocurre así cuando nos damos completamente a nosotros mismos, cuando trascendemos nuestro afán individualista y nos entendemos como criaturas. El sentirse criatura impide la soberbia y nos hace humildes y misericordiosos. Esta experiencia religiosa es, pues, condición de posibilidad de la razón poética. Por ello la filosofía que nos propone María Zambrano es pensamiento religioso, es saber de salvación que pone en comunicación a la persona con la realidad.

Una criatura que siente la realidad y al mismo tiempo se siente a sí mismo heterogéneo [sic] a ella. Conciencia de soledad al par que conciencia de participación, de trato. Mientras que el racionalista, aparte de que crea que la realidad se le da en una idea o pensamiento, cree también que sólo reduciendo la realidad a pensamiento puede entenderse con ella (Zambrano, 1989a, p. 20).

La fenomenología de lo divino, de Zambrano, trata de una indagación que apunta a la develación de lo que aparece. Se trata de un concepto heideggeriano y orteguiano; es búsqueda esencial, por tanto, búsqueda de la esencia sagrada, de lo profundamente humano que se muestra de múltiples maneras.

Agustín Andreu (2007), buen conocedor y confidente de María Zambrano, describe así el sentir originario: 
El presupuesto es que el 'conatus' del ser del hombre tal como lo conocemos tiene una circulación interior trinitariamente caracterizada, es decir, igual que tiene que dormir, respirar y digerir, la vida del hombre tiene, con carácter normal, pasos y traspasos desde el sentir originario a la expresión y desde ésta a la situación espiritual en sus diversos estadios y estados (Andreu, 2007, p. 170).

Todavía podemos preguntarnos: ¿qué le ocurre al ser si no se sitúa en el centro de sí mismo? La autora responde que vive exiliado, ubicado fuera como alguien externo que no habita el propio ser. Para expresarlo usa la imagen del naufragio: "todo da a entender que sólo 'in extremis' el hombre piense, y que naufrague por haberse resistido desesperadamente a hacerlo" (Zambrano, 1989b, p. 20).

La posible salida está en la persona, si esta admite un saber trascendental, saber de revelación. Por ello parte de la confesión, que es entrar en la propia conciencia para conocer no solo la exterioridad sino la interioridad donde encontramos la propia indigencia.

La confesión, más que ningún género literario, muestra lo que la vida tiene de camino, de tránsito entre aquel que nos encontramos siendo y el otro hacia el que vamos. [...] La confesión al revelarnos el camino entre uno y otro, entre el yo obscuro y el que ha alcanzado su unidad en su transparencia, hace posible la realización (Zambrano, 2004, p. 109).

El despertar del ser a sí mismo y a la realidad se da en el "sentir originario", en la afectividad y no en el concepto. Ser no va desligado del sentir. En la persona se dan simultáneamente estos dos actos, el acto de ser, como existir, y el acto de sentir siendo. La filósofa en sus escritos lo expresa así.

Todo aquello que puede ser objeto de conocimiento, lo que puede ser pensado o sometido a experiencia, todo lo que puede ser querido, o calculado, es sentido previamente de alguna manera; hasta el mismo ser que, si solamente se le entendiera o percibiese, dejaría de ser referido a su propio centro, a la persona (Zambrano, 1989a, p. 11).

Este sentir originario es un sentimiento que muestra en la persona dos ámbitos. Uno es el espacio de la apertura al mundo a través de la realidad, cómo la persona la vive y la sufre, Es el ámbito de la "alteridad". Y el otro, es el espacio interior, donde se da el apego de la persona a sí misma que llamaremos su "interioridad". El sentir originario se convierte para Zambrano en algo que nos mantiene ligados a nuestro interior $\mathrm{y}$, al mismo tiempo, invita a salir fuera, a trascender. 


\section{Conciencia abierta al otro: Piedad, fraternidad, misericordia y perdón}

Como se ha constatado, el entrar en las propias entrañas llevan al sentir originario que busca la unidad y la relación con lo otro. Así pues la interioridad unitiva y la alteridad relacional llevan a una "conciencia abierta al otro" (Zambrano, 2011a, p. 260).

Aunque se puede vivir la vida desde la simple exterioridad, como ocurre con el resto de seres vivos, la persona desde la interioridad está llamada a poner en juego las facultades de que dispone, "inteligencia autoconsciente e interrogativa, sensibilidad afectiva, autodeterminante y libre. Gracias a estas facultades puede procesar interiormente el significado de todo aquello que le interroga desde fuera" (Carrón de la Torre, 2012, p. 178).

Supone situarse en la interioridad del ser humano para la búsqueda de lo divino que en él habita. No es un salirse fuera de sí, sino que la persona se atiende a sí misma y busca en su interior la verdad. Sentir y saber que estar unidos a Dios es la mejor manera de permanecer en nosotros mismos. Este hombre nuevo es el ser interior agustiniano al que tantas veces la autora:

No quieras derramarte fuera; entra dentro de ti mismo, porque en el hombre interior reside la verdad; y si hallares que tu naturaleza es mudable, trasciéndete a ti mismo, mas no olvides que, al remontarte sobre las cimas de tu ser, te elevas sobre tu alma, dotada de razón. Encamina, pues, tus pasos allí donde la luz de la razón se enciende (San Agustín, 1976, p. 72).

Es un vivir que ha de comunicarse porque conlleva una implicación con todo ser humano con quienes formamos parte de un sistema, el género humano "Convivir quiere decir sentir y saber que nuestra vida, aun en su trayectoria personal, está abierta a la de los demás, no importa sean nuestros próximos o no; quiere decir saber vivir en un medio donde cada acontecer tiene su repercusión" (Zambrano, 1988, p. 16).

En la fenomenología de la religión que Zambrano traza en su obra El hombre y lo divino, señala la importancia de la piedad, "que supone el momento creativo del pensamiento y del comportarse humanamente" (Sánchez-Gey, 2009, p. 79).

La piedad se muestra como máxima forma de saber tratar con lo que está oculto a la razón dogmática. Se ubica más allá de una exclusiva manifestación del perdón. Es una actitud que lleva a saber reconocer la unicidad del ser y sus manifestaciones en la pluralidad de sus formas y, en sus contradicciones. La piedad, es una relación recíproca en la que vida y 
ser viviente se hallan influyéndose mutuamente. Piedad es un saber tratar con lo heterogéneo, con aquello que es diferente a la persona, es saber tratar con lo otro. Consiste en un sentimiento de comunión sin perder la individualidad del ser. No es reducible a la compasión por los animales o las plantas desde una conciencia ecológica. Ni tampoco a la tolerancia que mantiene una distancia respetuosa con quien no se sabe tratar. "Comunión en la diferencia, trato que no conlleva una voluntad reductora de la pluralidad a un único plano homogéneo de lo real, sino que respeta y busca la relación con la amplia gama cromática que la realidad presenta" (Gómez Blesa, 2008, p. 193). Por tanto comunión amplia, que se abre a la heterogeneidad del ser.

Podemos deducir que, si la piedad supone el adecuado trato con la realidad, y la realidad constituye siempre ese fondo misterioso esquivo a la razón, podemos llegar a definir la piedad como "saber tratar con el misterio" (Zambrano, 1989a, p. 22).

Por un lado encontramos una realidad exterior al sujeto, algo que lo circunda; por otro lado, una realidad interior, que se manifiesta en las entrañas. Por esto Zambrano afirma: "El misterio no se halla fuera; está dentro y en cada uno de nosotros, al par que nos rodea y envuelve. En el vivimos, y nos movemos. La guía para no perdernos en él, es la piedad" (Zambrano, 1989a, p. 23).

La filosofa veleña nos propone la recuperación de la piedad, la habilitación en la persona del sentimiento piadoso.

Para comprender el concepto de piedad en la filosofía de la autora, nos ayudan algunos personajes que ella analiza detalladamente en sus escritos. Es el caso de Antígona una mujer devorada por la piedad. La recreación que realiza Zambrano del personaje mítico, es "poiesis" de la persona nueva. Antígona como persona que se hace a sí misma, sacrificada por amor genera un modo nuevo de relaciones, la fraternidad.

Varios escritos dedica María Zambrano a la figura de esta tragedia griega. La primera en la obra Delirio de Antígona, publicada en 1948, encarnada en una joven muchacha que actúa conducida "por el amor y la piedad". A través de la narración muestra que las leyes del corazón son más fuertes que las de la razón. Se aleja de la idea de tragedia como escrito literario para acercarse a un concepto que entraña una significación religiosa.

En el segundo escrito sobre el tema, La tumba de Antígona, del año 1967, haciendo referencia a la filosofía griega y al mundo clásico grecolatino, realiza una interpretación nueva del personaje. Esta recreación le permite hacer una reflexión alegórica sobre la lucha entre el bien y el mal, la opresión de los poderosos y sus injusticias; las guerras fratricidas; la 
unión familiar ante los problemas y la dulzura como elemento dinamizador de las relaciones humanas. De este modo para María Zambrano, Antígona adquiere un matiz universal, es arquetipo de la humanidad.

La tumba de Antígona es la única obra teatral que escribió Zambrano. Para la autora el teatro es ese espacio donde se puede invocar el misterio que sostiene la vida humana, el lugar donde es posible hacer sagrado cada instante. La obra transcurre en la tumba, allí Antígona es visitada por personajes ficticios y reales. El lugar se transforma en espacio de encuentros, que le permiten, a través de la relación y la comunicación, superar la conciencia identitática, cerrada sobre sí misma, y llegar a ser prototipo de una persona nueva.

La estructura simbólica de la obra le ofrece a la autora la posibilidad de hacer una confesión de la propia experiencia, al estilo agustiniano. El mundo imaginario presente en La tumba de Antígona llega a ser una biografía o historia del alma personal y colectiva con el que se identifica Zambrano. Ella muestra su propio camino de desprendimiento personal, el desapego de sí misma que lleva a abrir un horizonte a la piedad, al nacimiento de la conciencia humana y a la transcendencia.

Para alcanzar esa plenitud y esa profundidad en sus reflexiones María Zambrano ha debido padecer muchos reveses en su vida: exilio, carencia de recursos, abandono y muerte de personas cercanas, etc. Todo asumido desde la razón de las entrañas, adquiriendo esa experiencia vital que le llevó a poder afirmar cuando regresa a España que ya no queda nada de rencor "Pues el rencor nace de lo que no logra, trabajando siempre, ser escuchado". (Zambrano, 2005, p. 69).

Zambrano lleva a Antígona a deshacer el nudo del laberinto familiar, de este modo queda establecida la diferencia entre la ley de las personas y la de los dioses, y aparece la verdadera ley, la del perdón y de la piedad, que en opinión de la autora sobrepasa a las dos anteriores. Inicia el camino humano de la vida individual libre, cerrando el proceso trágico mediante el sacrificio que la libera de la carga de culpabilidad de su linaje, heredada y genérica. La joven es culpable desde la cuna y su sacrificio responde a una voluntad de ruptura con la predestinación marcada por los dioses. De ahí que diga la autora malagueña, con Antígona se abre un horizonte cristiano.

La tarea de Antígona es la fraternidad, en la tragedia zambraniana, los hermanos llegan a la tumba juntos. Allí se establece un diálogo entre los tres para descubrir los lazos de hermanamiento. Ambos le reclaman una hermandad exclusiva pero ella declama con fuerza: "Y yo, sí, soy hermana vuestra, de los dos como he probado" (Zambrano, 2011b, p. 1152). La 
misión que Zambrano atribuye a la joven protagonista de la tragedia es la de hermanar, la de igualar, la de mediar entre los hermanos y más allá del círculo familiar entre la vida y la muerte; por esto "Antígona no vino 'a vivir su vida'. Si Antígona hubiera vivido 'su vida' ¿cómo hubiese podido desatar el terrible nudo, verificar la reconciliación?” (Zambrano, 1995, p. 70).

Esta fraternidad que es la condición que hace posible la justicia e impulsa a aspirar a la igualdad de todos los seres humanos, la caridad. En Zambrano la fraternidad y el amor, tienen una resonancia de ámbito cristiano.

La misericordia, para la autora, es una categoría que surge desde el interior de la persona, se trata de un saber que ha de abandonar la soberbia de la razón, la soberbia de la vida:

Nada más infecundo que la rebeldía, aquella que mantiene al hombre suelto, ensimismado, sin hondura; confinado en la miseria del aislamiento, que algunos se empeñan en llamar libertad o independencia; que algunos otros llegan hasta llamar poderío, pero que es solo soberbia (...). En suma, este saber nuevo tendrá que ser un saber de reconciliación, de entrañamiento (Zambrano, 1987b, pp. 110-111).

Por tanto, se puede afirmar que la misericordia, para ella, es algo más que una institución benéfica, consiste en una forma de ser, dejando la simple apariencia, se sitúa en el interior de la persona. Esta misericordia se apoya en una razón humilde, una razón que no toma represalias contra el racionalismo, rebasándola, superándola, pero sin disputas. Una razón que actúa sin definirse ni separarse, mezclándose, por tanto renuncia a la abstracción para no despegarse de las entrañas humanas.

El pensamiento zambraniano sobre la misericordia se recoge en los comentarios y escritos sobre Benito Pérez Galdós. Esto es lo que descubre y constata:

Humilde, dispersa, misericordiosa más que ninguna otra es la obra de Galdós; trasparenta como ninguna otra las cuestiones más decisivas de nuestra historia, los sucesos más transcendentes de nuestro ayer y el fuego vivo del presente. Ahí está como un inmenso regalo para satisfacer nuestra necesidad de conocimiento, nuestra extremada pobreza en el saber de aquello que más nos importa (Zambrano, 1986, p. 126).

Frecuentemente, la autora malagueña, expone su pensamiento trazando círculos con su escritura alrededor de algunas figuras, que analiza detalladamente; se trata de personajes presentes en distintas obras, volviendo a ellos una y otra vez, como se ha visto. Este es el caso de Nina, personaje central de la obra Misericordia de Benito Pérez Galdós (2003). La novela citada está presente en muchas de sus obras, en España, sueño 
$y$ verdad, introduce el personaje; volviendo sobre él en Los intelectuales en el drama de España, donde lo trata ampliamente comentando la novela de Pérez Galdós del mismo título. También, en La España de Galdós. Se puede afirmar que alrededor de una docena de veces aparece la obra de este autor en la reflexión y escritura zambraniana.

Siguiendo a la Real Academia Española recogemos las ideas centrales de la novela galdosina: Misericordia es una novela emblemática sobre la marginación social; una crítica intemporal a la sociedad y a los valores en que se sustenta la convivencia. En ella Pérez Galdós refleja la vida de las clases más humildes del Madrid de finales del siglo xix. Narra la historia de Benigna, también, llamada Nina, mujer de gran humanidad que sirve en una casa de la burguesía madrileña, arruinada y decadente, y se ve obligada a mendigar para ayudar económicamente a sus señores. El or100 gullo y la importancia de guardar las apariencias que caracterizan a estos amos, contrastan con la bondad de Benigna, condenada a sobrevivir en un entorno hostil, sin perder su dignidad. Para los amos, el futuro no es posible sin su perdón y sin su misericordia.

¿Cómo trata el tema María Zambrano? Se acerca a cada uno de los personajes de la novela, intentando aprehender sus movimientos trascendentes, sus proyectos o los sueños de existencia que tienen. Benigna de Casia es el personaje que encarna estos sentimientos, ella la describe así: "Atrae como ninguna otra la figura de Benigna en Misericordia; por lo que es en sí misma -agua pura y viva brotando entre escombros- y porque es ella la clave de todo este mundo complicado. Agua y roca a la vez" (Zambrano, 1986, p. 138).

En el mundo de Benigna se descubre que las personas pueden seguir en pie porque unas manos incansables, unas espaldas valerosas las sostienen: las manos y el corazón infatigable de Nina, abogada de imposibles. Benigna pide limosna por ellos y para ellos: "Se está a la puerta de la iglesia de San Sebastián como una mendiga más, corretea por las calles y sube interminables escaleras, vence a diario el imposible y realiza el milagro continuo, continuo como el pan de cada día" (Zambrano, 1986, 138).

La interpretación de la autora continua así: "Benigna, la que a medida que avanza la historia se convierte en verdadero eje del mundo, en protagonista de la tragedia, en víctima y liberadora que paga por todos y a todos salva, a pesar de ser ella quien gana" (Zambrano, 1986, p. 144). La gran fuerza de Nina reside ante todo en la comprensión, facultad de comprensión, dirá ella, absorción de todo lo que la rodea y, a la vez, eliminación de todo aquello que pudiera envenenarla o detenerla; sobrevivir salvando todas las dificultades con naturalidad. "Es la fuerza inagotable de la vida 
transformándolo todo en vida" (Zambrano, 1986, p. 144). El corazón de Nina, lleno de amor y misericordia no se dejará llevar por las ingratitudes ni los desengaños, se sobrepone y se escapa del rencor y la amargura.

Para Nina es importante, y la autora lo sugiere para cada persona, hacer lo que le mande la conciencia y dejar que se "peleen aquellos por un hueso como los perros; los otros por un juguete como los niños, o estos por mangonear, como los mayores, y no reñir con nadie" (Zambrano, 1986, p. 145). Esto es porque ella vive en la luz y con su esfuerzo crea la libertad. "Desasida y apegada a un tiempo a las cosas, libre de la realidad y esclava suya a la vez; invulnerable y al alcance de la mano, dueña de todo y sirvienta de cada uno, Nina, en verdad, es Misericordia" (Zambrano, 1986, p. 145).

Es el camino que muestra la filósofa para lograr el trascender de la persona. Su actitud es la del místico, la de la persona que descubre los misterios. "Según Santo Tomás la mística ¿no es el conocimiento experiencial de Dios? Pues en eso estamos queramos o no queramos" (Zambrano, 2002, p. 80). Porque para Zambrano "la persona cristiana, [...], no tiene límite, ni para sus fuerzas, ni para su vida, ni para su muerte" (Zambrano, 2004, p. 113). Es la perspectiva infinita, que ella sitúa en el fondo de la persona, en la interioridad.

En esta clave de la conciencia abierta al otro hay otra actitud que Zambrano propone para la transformación de la vida y de la importancia crucial en el ámbito religioso, el perdón.

De especial relevancia son los manuscritos: Del perdón, M-97, escrito en febrero del año 1965 y El lugar del perdón, M-103, de marzo del mismo año ${ }^{3}$. Ambos aportan luz a la temática de las acciones concretas que proponemos, a partir de las cuales la persona se transciende.

En el titulado Del perdón, la filósofa llama la atención sobre la importancia y hermosura de esta palabra, que ha de ser como una joya despojada de adherencias y revitalizada en su contenido. El manuscrito tiene carácter introductorio al tema, lo encuadra y da la clave: "Hay palabras gastadas por su uso continuo que de ellas se hace hasta caer como hojas sin savia en un terreno donde su significación se pierde en el 'humus' del lenguaje usual que tantas formas del pensamiento devora" (Zambrano, 2015a, p. 505).

La autora recurre a la comparación del concepto perdón con una piedra preciosa para llevar a comprender su importancia. La palabra perdón es imagen, recurso tan frecuente en la literatura de Zambrano, para captar la luz, la fuerza y el peso específico del perdón "está ahí con su pura presencia cargada de sentido y de significación, palabra rescatada, 
sobrecogedora en toda su integridad" (Zambrano, 2015a, p. 505). Pero la palabra perdón ha sido vaciada de contenido y, entonces, se sumerge, dice la autora, en un uso martilleante y efímero del que es necesario rescatarla, porque no es el perdón simple moneda de cambio frente a un favor o una solicitud. Por esto, continúa afirmando:

Y a quien esto escribe costaría grande fatiga el explicar al educado en una religión no cristiana como los cristianos hemos venido a usar de este modo la palabra cifra y clave de todas las que nos donara Nuestro Señor. ¿ $\mathrm{O}$ es que no sucederá igualmente en las demás religiones? Y las palabras sacras habranse [sic] hecho en sus civilizaciones correspondientes, cuotidianas, formularias, opacas (Zambrano, 2015a, p. 505).

Propone, así, recuperar en el concepto perdón la fuerza del lenguaje, porque "las palabras nos rigen. Habría por lo menos que redescubrir de tanto en tanto el sentido y valor de algunas. La palabra 'perdón' merece bien ser la primera de todas entre nosotros. Lo que intentaremos menos que modestamente hacer" (Zambrano, 2015a, p. 506).

El segundo Manuscrito El lugar del perdón, la autora concreta que "el lugar donde tal acontecimiento sucede, es el alma y aun antes el corazón, cuando de perdonar se trata" (Zambrano, 2015b, p. 513). Indica que es una acción que se elabora en el corazón y, como gota de aceite, se expande e invade el pensamiento y la persona por entero hasta lo más recóndito.

Continúa la filósofa malagueña, buscando lugares de perdón: "Hay puertas llamadas del perdón, hay muros, hay templos y hasta el monte sagrado entre todos, el del Calvario para impetrar perdón y darlo" (Zambrano, 2015b, p. 513). Un perdón que une a los seres humanos y "que el perdón es uno, indivisible, si se recibe se ha de dar al mismo tiempo, y si se da de alguna manera por invisible que sea, se recibe" (p. 513).

Como se viene afirmando, el perdón se inicia en el corazón, por tanto, para la filósofa su lugar es el centro de la persona, dentro de sí misma, espacio íntimo, secreto, que facilita y realiza la alquimia del perdón. Para esto, Zambrano recurre a Agustín de Hipona: "Cuando la vida no se ha convertido anda confusa y dispersa" (Zambrano, 2001, p. 73). Y para convivir es "necesario conocerse, dejar de ser un extraño para sí mismo, no haber llegado a poseer intimidad consigo mismo o haberla perdido; andar enajenado, huésped extraño en la propia casa" (Víllora Sánchez, 2015a, p. 184).

Así pues, el lugar del perdón es el interior que como agua corre, inunda y trasmuta el pensamiento. $Y$ es tal la radicalidad que presenta 
la filosofía de Zambrano, en este punto, que llega a afirmar: "Cuando el perdón tiene verdadera importancia se muestra en contra del juicio" (Zambrano, 2015b, p. 513). Lo razonable y las razones juiciosas quedan al margen del perdón para la autora. El juicio es, para ella por principio, lo más indisoluble del pensamiento. Recurre, una vez más a las metáforas para establecer la relación entre el juicio y el perdón. "Si el perdón es agua, el juicio es diamante o metal encendido y llameante, diamante si se trata de un juicio en el cual ha cristalizado todo un pensamiento" (Zambrano, 2015b, p. 513).

La autora considera un paso más: la dimensión social del perdón. "Hay ocasiones en que el perdón puede confundirse con la falta de dignidad o con la dejadez o con un calcular en vista de finalidades que nada tengan que ver con la moral suprema del perdón" (Zambrano, 2015b, p. 513). Sin duda aquí, reside el fondo de la cuestión del perdonar al prójimo. ¿Cómo llegar al perdón en este horizonte del pensamiento? María Zambrano de nuevo muestra su método y sugiere entrar en sí mismo:

Entonces el perdón llega solo, porque parece ser el lugar donde nace es el del conocimiento de nosotros mismos, no del yo y del tú, sino del nosotros, de ese 'nosotros' que formamos toda la humanidad, incluidos los individuos de mayor belleza y esplendor y los que más hondos motivos nos ofrecen par avergonzarnos de nuestra condición (Zambrano, 2015b, p. 515).

En el interior de sí mismo resulta ser hasta justo y "no generoso el perdonar; pues que en virtud de esta unidad del género humano participamos de la gloria de la belleza, y recogemos frutos de todo orden de los que fueron y de los que son mejores que nosotros" (Zambrano, 2015b, p. 513). Resuena el eco de la participación de la persona en todo lo humano, coparticipación universal que humaniza, que es fuente de fraternidad y no permite desconectar del otro.

El sentimiento es el último lugar donde la autora coloca el perdón. "Si cada ser humano ocupara el lugar adecuado dentro de nuestra alma y dentro también de la sociedad, el perdón sería cosa fácilmente hacedera" (Zambrano, 2015b, p. 515). Así, prepara ese perdón total que llega por la gracia, pero no sin el esfuerzo personal, afirmando que la persona es responsable de buscar un perdón incondicional. "No tendré pues enemigo" como dice en su artículo Adsum (Zambrano, 1998, p. 29).

Vivir desde la profundidad entrando en sí misma, adquiriendo en las vivencias y acontecimientos un saber de experiencia hace posible asirse al perdón, y va transformando la vida. La piedad, la fraternidad y la 
misericordia acciones justas antes que generosas nos conducen hacia los demás. Así, adentrarse en un saber de experiencia, un saber de salvación, es clave para comprender la transformación de la vida a la que nos invita María Zambrano.

\section{Conclusión: la religión saber de salvación}

El pensamiento de María Zambrano sugiere la salida de la crisis de la modernidad, la recuperación del sentir, del sentimiento íntimo de Dios. No basta con pensar en lo divino, pues Dios no puede quedar transformado en una entelequia de la razón, sino que hay que hacer el esfuerzo por recuperar a ese Dios cristiano del amor, a ese Dios cordial que despierta a la piedad, a la misericordia, a la fraternidad universal, a pertenecer y participar en el mundo.

María Zambrano anduvo un camino personal, que quiso convertir en método, es la razón poética. Esta razón se alimenta de la observación, la intuición, la escucha atenta del mundo interior, de la circunstancia y del entorno que la rodea. Esta es, razón poética que como gota de aceite recorre las entrañas de la persona para germinar un ser nuevo.

Una razón cargada de misericordia, amor y piedad; son sentimientos que se orientan a la plenitud de la persona en su relación con los otros, y con el Otro.

$\mathrm{Al}$ entrar en el interior de sí misma, la persona encuentra el "sentir originario", que es lo sagrado, y se acerca a la realidad. Saber filosófico que cuenta con la interioridad de la persona, con su propia vivencia y experiencia, con la piedad, con lo divino...

La religiosidad no es adormecimiento ni entorpecimiento de la persona. Cuando lo religioso se vive de modo personal y despierto, tiende a ser afirmación propia y horizonte que se proyecta en el vivir y en el convivir dando sentido a la toda la existencia.

La misericordia del Dios revelado lleva a liberarnos de sus falsas imágenes; a superar la lucha con el Dios desconocido, y a quitar las máscaras en las que el ser humano se esconde. La propuesta zambraniana es una expansión religiosa que mire hacia adelante, con un futuro donde reine la esperanza ilimitada, porque la persona se siente transformada, con un saber nuevo, saber de salvación. 


\section{Notas}

1 La persona, ser que busca la transcendencia, que para ella será el eje de la actividad política, ética, religiosa y educativa (Sánchez-Gey, 2009, p. 190). En estas páginas no se desarrollan estos cuatro aspectos, algunos ya han sido abordados en otros artículos: Víllora Sánchez, C. (2014). En cuanto al aspecto de la construcción ciudadana, ver Víllora Sánchez, C. (2017).

2 Sobre la razón vital de Ortega y Gasset sugerimos una metáfora referida al bosque que recoge en las Meditaciones del Quijote (1984): "Este bosque benéfico que unge mi cuerpo de salud, ha proporcionado a mi espíritu una grande enseñanza. Es un bosque magistral, viejo como deben ser los maestros, sereno y múltiple. Además practica la pedagogía de la alusión, única pedagogía delicada y profunda. Quien quiera enseñarnos una verdad que no nos la diga: simplemente que aluda a ella con un breve gesto, gesto que inicie en el aire una ideal trayectoria, deslizándonos por la cual lleguemos nosotros mismos hasta los pies de la nueva verdad. Las verdades una vez sabidas, adquieren una costra utilitaria; no nos interesan ya como verdades, sino como recetas útiles" (pp. 108-109). Por tanto una razón que conduce a la búsqueda desde la propia circunstancia; en la descripción de la razón poética del presente artículo se puede apreciar el salto que dará Zambrano, razón que cuente con el sentir.

3 Sobre la publicación de estos manuscritos se tiene constancia de que El lugar del perdón, M-103, fue publicado en la revista puertoriqueña Semana, en el año 1965, actualmente, de difícil acceso. El manuscrito, según las investigaciones realizadas y consultada la Fundación María Zambrano, se puede aventurar que es inédito: Del Perdón, M-97. Dichos textos han sido publicados en Zambrano, M. (2015b).

\section{Bibliografía}

ANDREU, Agustín

2007 María Zambrano. El Dios de su alma. Granada: Comares.

BUNDGÅRD, Ana

2000 Más allá de la filosofía. Sobre el pensamiento filosófico-místico de María Zambrano. Madrid: Trotta.

CARRÓN DE LA TORRE, Antonio

2012 María Zambrano y San Agustín. Diafanidad de la persona y transparencia del corazón. Alemania: Academia Española.

CEREZO GALÁN, Pedro

2004 La desnudez extrema. Recuperado de: http://www.elcultural.com/revista/letras/ La-desnudez-extrema-por-Pedro-Cerezo-Galan/9366 [Consulta 24/7/2017].

GÓMEZ BLESA, Mercedes

2008 La Razón mediadora. Filosofía y piedad en María Zambrano. Burgos: Gran vía. ORTEGA Y GASSET, José

1984 Meditaciones del Quijote. En: J., Ortega y Gasset, Obras Completas, Vol. I: 1902-1916, 309-399. Madrid: Revista de Occidente-Alianza.

ORTEGA MUÑOZ, Juan Fernando

2010 Muerte y resurrección de la metafísica en María Zambrano. En: A. Sánchez Cuervo, A. Sánchez Andrés y Sánchez Díaz (Coords.), María Zambrano Pensamiento y exilio (pp. 193-226). Madrid: Biblioteca Nueva. 
PÉREZ GALDÓS, Benito

2003 Misericordia. Madrid: Edimat.

REAL ACADEMIA ESPAÑOLA

2013 Misericordia. Benito Pérez-Galdós. Recuperado de: https://goo.gl/g8w7Br [Consulta 24/7/2017].

REVILLA, Carmen, ed.

2013 La palabra liberada del lenguaje. María Zambrano y el pensamiento contemporáneo. Barcelona: Bellaterra.

SAN AGUSTÍN

1976 Confesiones. En: Obras completas, Vol. II. Madrid: BAC.

SÁNCHEZ-GEY, Juana

2009 El saber de la experiencia. Metafísica y método en María Zambrano. En: $V$ Congreso Internacional sobre la vida y obra de María Zambrano Tomo II (pp. 189-197).

VÍLLORA SÁNCHEZ, Carmen

2014 Archipiélago. Revista Digital de Educación. 2, 113-136. Recuperado de: https://goo.gl/o5f9Dj [Consulta 24/7/2017].

2015a Renacer, para no vivir exiliados del ser. María Zambrano: el amor y la misericordia, camino para salir de la oscuridad y de la dispersión. Estudios Filosóficos, LXIV (185), 175-206.

2015b El pensamiento religioso de María Zambrano. María Zambrano; El amor y la misericordia, como camino para salir de la oscuridad y de la dispersión. Saarbrücken: Publicia.

2017 Aportación de María Zambrano a la Construcción de la Ciudadanía. RES Revista de Educación Social, 24, 451-461.

ZAMBRANO, María

1986 Senderos. Barcelona: Anthropos.

1987a A modo de Autobiografía. Anthropos. Revista de Documentación Científica de la Cultura, 70/71, 69-83.

1987b Pensamiento y poesía en la vida española. Madrid: Biblioteca Nueva.

1988 Persona y democracia. La historia sacrificial. Barcelona: Anthropos.

1989a Para una historia de la piedad. Málaga: Torre de las Palomas.

1989b Notas de un método. Madrid: Mondadori.

1990 Claros del bosque. Barcelona: Seix Barral.

1991 Carta a Rafael Dieste, [Habana 7 de noviembre de 1944]. Boletín Galego de Literatura, 5, 101-103.

1992 El pensamiento vivo de Séneca. Madrid: Cátedra.

1995 Nacer por sí misma. Madrid: Horas y Horas.

1998 Delirio y destino: Los veinte años de una española. Madrid: Centro de Estudios Ramón Areces.

2001 La confesión género literario. Madrid: Siruela.

2002 Cartas de La Pièce. Correspondencia con Agustín Andreu. Valencia: Pre-textos y Universidad Politécnica.

2003 Unamuno. Madrid: Debate.

2004 La agonía de Europa. Valencia: Universidad Politécnica de Valencia.

2005 Hacia un saber sobre el alma. Madrid: Alianza.

2011a El hombre y lo divino. En: M. Zambrano, Obras Completas III (pp. 21-359). Madrid: Galaxia Gutenberg. 
2011b La tumba de Antígona. En: M. Zambrano, Obras Completas III (pp. 11011168). Madrid: Galaxia Gutenberg.

2015a Del perdón M-97. En: C. Víllora Sánchez, El pensamiento religioso de María Zambrano. María Zambrano: El amor y la misericordia, como camino para salir de la oscuridad y de la dispersión (pp. 503-505). Saarbrücken (Alemania): Publicia.

2015b El lugar del perdón M-103. En: C. Víllora Sánchez. El pensamiento religioso de María Zambrano. María Zambrano: El amor y la misericordia, como camino para salir de la oscuridad y de la dispersión (513-518). Saarbrücken: Publicia.

Fecha de recepción del documento: 17 de julio de 2017 Fecha de revisión del documento: 10 de agosto de 2017 Fecha de aceptación del documento: 15 de septiembre de 2017 Fecha de publicación del documento: 15 de enero de 2018 